\title{
The Maxillary Lateral Incisor Agenesis: A Case Report and a Literature Review
}

\author{
I Chafi*, A Elaouame and L Ousehal \\ Department of Dentofacial Orthopedics, Faculty of Dental Medicine, Morocco
}

Submission: October 08, 2020; Published: October 22, 2020

*Corresponding author: I Chafi, Department of Dentofacial Orthopedics, Faculty of Dental Medicine, Mers Sultan, Casablanca, Morocco

Abstract

In his daily practice, the orthodontist is regularly asked to treat patients with one or more missing teeth. Considering their functional and esthetic specificities, and the relatively high frequency of agenesis, the Maxillary Lateral Incisor Agenesis (MLIA), either unilateral or bilateral, has recorded prevalence rates varying between 1.9 and $4.9 \%$. The following case-report represents the trouble and treatment management of a 16-years-old female patient with a congenitally missing upper lateral incisor associated to skeletal class III malocclusion. After an interdisciplinary evaluation for the proper treatment plan, whether it should be treated by orthodontic space closure or by space opening and implantation, the treatment option was of an orthodontic space opening. We were thus able to achieve a manageable treatment that best meets the patient's needs.

Keywords: Agenesis; Lateral incisor; Orthodontic population; Prevalence; Space opening

Abbreviations: MLIA: Maxillary Lateral Incisor Agenesis; CCTD: Consultation and Treatment Center; FPD: Fixed Partial Dentures

\section{Introduction}

Congenitally missing teeth are as a result of poorly developed tooth germs resulting in non-differentiation of dental tissues, [1], it is considered one of the most common anomalies of dental development, [2]. The prevalence of agenesis of permanent teeth varies among countries and races [1]. According to many studies, the prevalence of teeth agenesis varies between 6,7 and $9 \%(2-3-4-5)$, the most frequent agenesis concerns the maxillary lateral incisors and the second mandibular premolars [2-4,6]. The Maxillary Lateral Incisor Agenesis (MLIA), either unilateral or bilateral, has recorded prevalence rates varying between 1,9 and 4,9\% [1,7-10]. Mostly, this anomaly is associated to many skeletal and dental anomalies. Reduced or peg-shaped maxillary lateral incisors in patients with unilateral MLIA, maxillary canine eruption anomalies as ectopic eruption, impaction or tendency for mesial angulation, or even agenesis of other teeth are the most frequent dental anomalies recorded in MLIA cases [7,10,11]. Moreover, Patients with maxillary lateral incisor agenesis showed a significant tendency for skeletal Class III compared with the general population, which could be attributed to maxillary hypoplasia $[8,10]$.

\section{Case Report}

\section{Diagnosis}

A 16-years-old female patient was referred to the Department of Dento-Facial Orthopedics of the Dental Consultation and Treatment Center (CCTD) of the Ibn Rochd University Hospital in Casablanca, Morocco, with an aesthetic chief complaint which was the anterior crossbite. No pathological background information was reported according to her medical history. No hereditary field was recorded. The clinical examination revealed the absence of both maxillary lateral incisors, carious lesions on the first molars, concerning the inter-arch relationship, we recorded a cross-bite from 14 to 25, a class III molar relation, and a class II canine relation (Figure 1). The anamnestic information of the patient revealed an atypical swallowing and a phonation disorder. Her skeletal and alveolar structures appeared to be normal in panoramic radiographs, this one confirmed the Maxillary Lateral Incisor Agenesis (MLIA) diagnosis. (Figure 1). Cephalometric analysis showed that the mandible was protrusive relative to the maxilla, which led to a skeletal class III diagnosis $\left(\mathrm{ANB}=3^{\circ}\right.$, $\mathrm{AoBo}=-4 \mathrm{~mm}$ ). Moreover, the patient had a skeletally long face ( $\mathrm{GoGn} / \mathrm{SN}=38^{\circ}, \mathrm{FMA}=30^{\circ}$ ). In addition, both the upper and lower incisors were retroclined $\left(\mathrm{I} / \mathrm{NA}=13^{\circ} / 2 \mathrm{~mm}, \mathrm{i} / \mathrm{NB}=25^{\circ} / 4 \mathrm{~mm}\right.$, IMPA $=80^{\circ}$ ) (Table 1$)$.

\section{Treatment goals}

The main goals of treatment were to attain a pleasing profile by obtaining normal anterior overbite, to get a bilateral class I canine and molar relationship and to correct the upper and lower incisors' retroclination. 


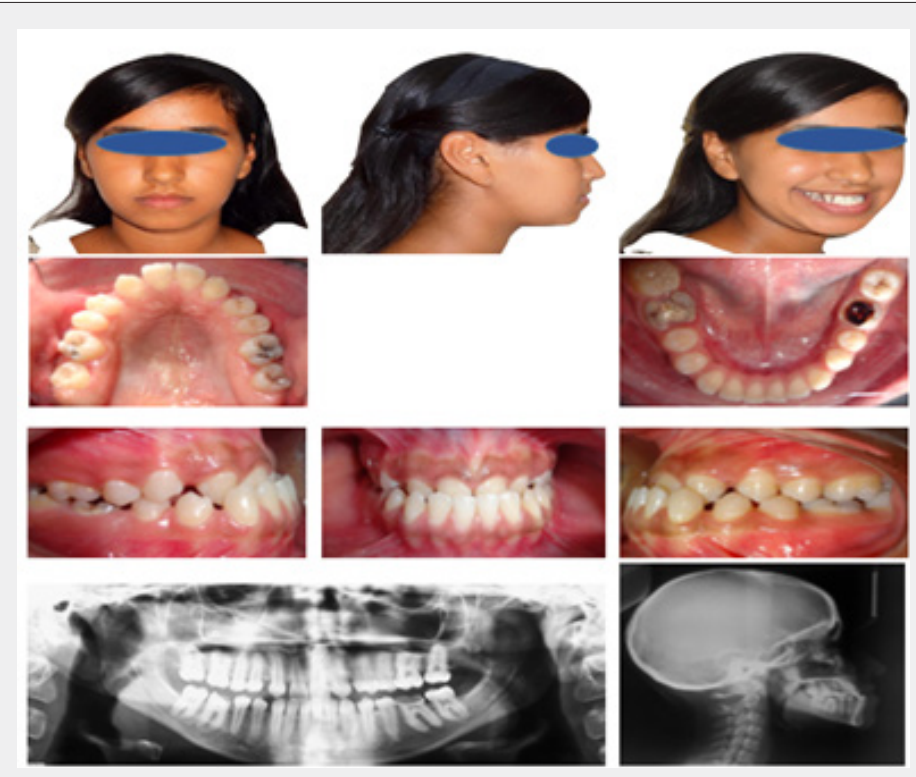

Figure 1: Pretreatment extraoral and intraoral photographs, panoramic and lateral cephalometric radiography.

Table 1: Pre-treatment Cephalometric measurements.

\begin{tabular}{|c|c|c|}
\hline Parameter & Norm & Pre-treatment \\
\hline SNA $\left({ }^{\circ}\right)$ & $82^{\circ}$ & $87^{\circ}$ \\
\hline $\operatorname{SNB}\left({ }^{\circ}\right)$ & $80^{\circ}$ & $85^{\circ}$ \\
\hline $\operatorname{ANB}\left({ }^{\circ}\right)$ & $2^{\circ}$ & $3^{\circ}$ \\
\hline AoBo (mm) & $-2 \mathrm{~mm}$ to $+2 \mathrm{~mm}$ & $-4 m m$ \\
\hline $\mathrm{I} / \mathrm{NA}\left(^{\circ}\right)$ & $22^{\circ}$ & $13^{\circ}$ \\
\hline $\mathrm{I} / \mathrm{NA}(\mathrm{mm})$ & $4 \mathrm{~mm}$ & $2 \mathrm{~mm}$ \\
\hline $\mathrm{i} / \mathrm{NB}\left({ }^{\circ}\right)$ & $25^{\circ}$ & $25^{\circ}$ \\
\hline $\mathrm{i} / \mathrm{NB}(\mathrm{mm})$ & $4 \mathrm{~mm}$ & $4 \mathrm{~mm}$ \\
\hline $\mathrm{I} / \mathrm{i}\left(^{\circ}\right)$ & $131^{\circ}$ & $141^{\circ}$ \\
\hline GoGn/SN $\left(^{\circ}\right)$ & $32^{\circ}$ & $38^{\circ}$ \\
\hline FMA $\left(^{\circ}\right)$ & $25^{\circ}+/-3$ & $30^{\circ}$ \\
\hline FMIA $\left(^{\circ}\right)$ & $67^{\circ}+/-3$ & $70^{\circ}$ \\
\hline $\operatorname{IMPA}\left({ }^{\circ}\right)$ & $88^{\circ}+/-3$ & $80^{\circ}$ \\
\hline
\end{tabular}

\section{Treatment plan and progress}

To reach these goals, we decided for an orthodontic treatment with space opening for the missing maxillary lateral incisors. The treatment comprised a first phase of alignment, levelling and correction of rotations using flexible wires NiTi arches (0.14; $0.16 ; 16.22)$, which were followed by progressive heavy StainlessSteel arches $(17.25 ; 19.25)$. Then, a phase of correction of the denture by a lower incisor retraction and space opening for 12-22 by using NiTi orthodontic open coil springs, followed by setting up a Class I occlusion and a correct intercuspidation thanks to intermaxillary elastics traction, then ; finishing and removing of the device. Upper and lower fixed retentions were put right after the device removal. Composite veneers with brackets were put in place during the treatment in order to foreshadow the future prosthesis, to estimate the space to be opened and to meet the aesthetic demand of the patient.

\section{Treatment results}

After 26 months of treatment, we were able to meet the patient's treatment objectives, by correcting her profile, installing a canine class 1 occlusion, and by opening the space for the agenized lateral incisors. Prosthetic rehabilitation is envisaged for the patient. In the meanwhile, a thermoformed gutter with veneers in the sites of 12-22 was realized and put in place in order to camouflage the esthetic deficit in this smile exposed area (Figure 2) \& (Table 1).

Table 2: Post-treatment Cephalometric measurements.

\begin{tabular}{|c|c|c|}
\hline Parameter & Norm & Post-treatment \\
\hline SNA $\left({ }^{\circ}\right)$ & $82^{\circ}$ & $85^{\circ}$ \\
\hline $\operatorname{SNB}\left({ }^{\circ}\right)$ & $80^{\circ}$ & $83^{\circ}$ \\
\hline $\operatorname{ANB}\left({ }^{\circ}\right)$ & $2^{\circ}$ & $2^{\circ}$ \\
\hline AoBo (mm) & $-2 \mathrm{~mm}$ to $+2 \mathrm{~mm}$ & $-2 \mathrm{~mm}$ \\
\hline $\mathrm{I} / \mathrm{NA}\left({ }^{\circ}\right)$ & $22^{\circ}$ & $20^{\circ}$ \\
\hline $\mathrm{I} / \mathrm{NA}(\mathrm{mm})$ & $4 \mathrm{~mm}$ & $3 \mathrm{~mm}$ \\
\hline $\mathrm{i} / \mathrm{NB}\left(^{\circ}\right)$ & $25^{\circ}$ & $19^{\circ}$ \\
\hline $\mathrm{i} / \mathrm{NB}(\mathrm{mm})$ & $4 \mathrm{~mm}$ & $3 \mathrm{~mm}$ \\
\hline $\mathrm{I} / \mathrm{i}\left({ }^{\circ}\right)$ & $131^{\circ}$ & $140^{\circ}$ \\
\hline GoGn/SN $\left(^{\circ}\right)$ & $32^{\circ}$ & $40^{\circ}$ \\
\hline FMA $\left(^{\circ}\right)$ & $25^{\circ}+/-3$ & $30^{\circ}$ \\
\hline FMIA $\left(^{\circ}\right)$ & $67^{\circ}+/-3$ & $75^{\circ}$ \\
\hline $\operatorname{IMPA}\left({ }^{\circ}\right)$ & $88^{\circ}+/-3$ & $75^{\circ}$ \\
\hline
\end{tabular}



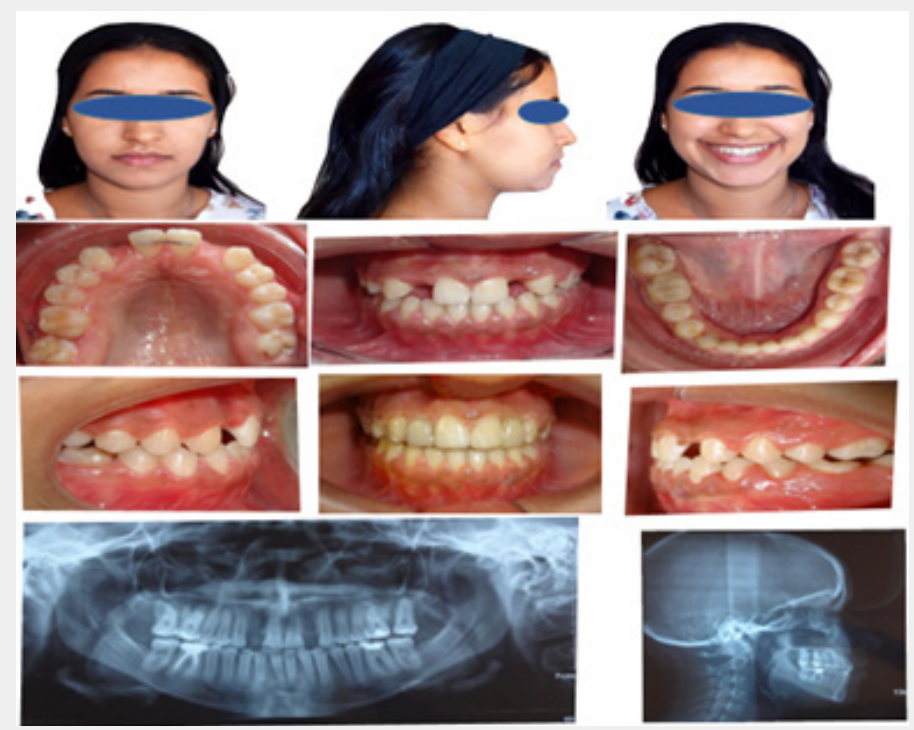

Figure 2: Post treatment extraoral and intraoral photographs, panoramic and lateral cephalometric radiography.
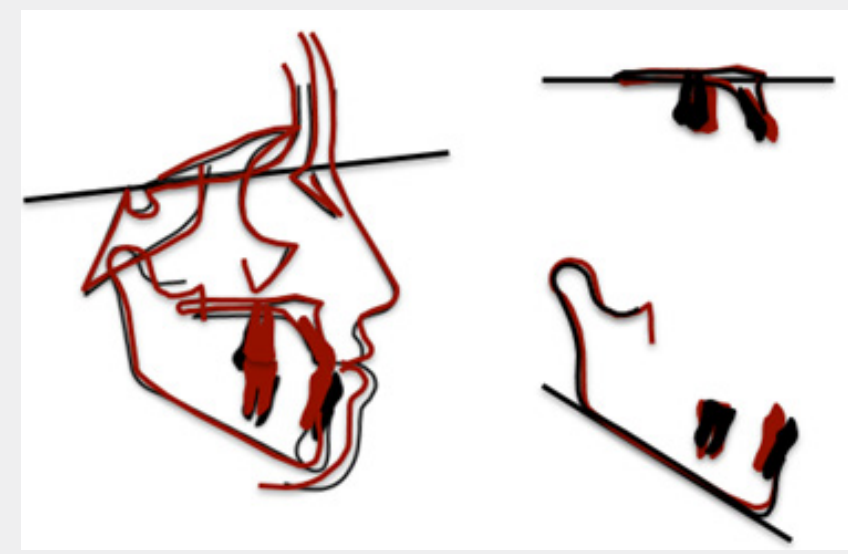

Figure 3: Cephalometric superimposition.

\section{Discussion}

The incidence of maxillary incisor agenesis is prevalent [12], clinicians are faced with many treatment options that were the subject of many studies. Orthodontics is an inevitable runway for patients with Maxillary Lateral Incisor Agenesis, either for orthodontic space closure by a canine substitution, or space opening and prosthetic rehabilitation with a single-tooth implant-supported prosthesis or with a tooth-supported bridge [13]. Space closure with a canine substitution can be a good therapeutic option, and have satisfying results, with a good costrisk-benefit ratio. Less cost and time compared to space opening and prosthetic rehabilitation, avoidance of the need for tooth extractions in cases of severe crowding are some of many benefits of this option [13]. One other major advantage of orthodontic space closure especially for young patients with lateral incisor agenesis and a coexisting malocclusion is the permanence of the finished result and the possibility to complete the treatment at an early age [14]. However, this option represents a challenge in terms of aesthetic rehabilitation, particularly in patients with unilateral agenesis. In fact, the main problem about space closure is when matching size, color and shape of the canines to mimic lateral incisors and the first premolars to imitate the mesialized canines. Some studies aimed to evaluate the perception of attractiveness of missing maxillary lateral incisors replaced by canines through photographs have concluded that darker canine color and a pronounced tip morphology of a substituted canine are rated as the most unattractive. Therefore, perceptions of dental esthetics can vary between dental professionals and laypersons. In fact, Nonprofessional observers considered a simple dental reshaping of the canine to be attractive, while the dental professionals considered gingival and crown reshaping to be more esthetic [1517]. 


\section{Advances in Dentistry \& Oral Health}

Nevertheless, this option can have some inconveniences such as the lack of development of canine guidance, flattening of the facial profile with an increase in the nasolabial angle and a possible predisposition to a Class III relationship [18]. For our patient, we decided for a Space opening and prosthetic rehabilitation which is as well as chosen option for patients with MLIA, in terms of giving the possibility of ideal intercuspidation with canine-protected occlusion [19]. Absence of dental crowding, concave profile characterized by a retrusive upper lip, premaxilla deficiency (Skeletal Class III) were the main reasons that justified our choice for the space opening, and with whom the space closure would cause more harm than good. Different restorative approaches may be employed in the agenesis area, such as resin bonded fixed partial dentures (FPD), cantilevered FPDs, and conventional full-coverage FPDs, or even by single-tooth implants and implant-supported crowns [19]. Single-tooth implant-supported prosthesis can be an excellent option in terms of survival rates that can reach up to $96 \%$ over a 20 -year period [20], However, it is not possible to exclude some negative aspects of this therapeutic approach; such as progressive infraocclusion of the prosthetic crown, due to the continuous eruption of the adjacent teeth [13], as well as a higher prevalence of gingival inflammation, increased probing depths and lack of dental papilla [19], resorption of the labial cortical plate and darkening of the overlying labial gingiva [13]. These problems can severely compromise esthetics, and their remediation is difficult. Therefore, this option could not be envisaged for all patients, not only because of these disadvantages, but also because of its relatively high cost and its medical contraindications. Tooth supported prosthesis is as well a good alternative for patients with MLIA, bringing together high survival rates and satisfying esthetic results. The resin-bonded fixed dental prostheses have in addition the advantage of being more conservative which can avoid the potentially damaging sequelae of traditional fixed prostheses, which is especially problematic in young patients with large pulp chambers [12]. Nevertheless, these prosthetic choices respect less the periodontal health, and are considered to be aesthetically worse than orthodontic space closure treatment [21].

\section{Conclusion}

The Maxillary Lateral Incisor Agenesis (MLIA) presents a challenge for the dental team. Many therapeutic options exist, but also many elements guide the treatment choice as the age of the patient, the type of facial profile, the type of sagittal malocclusion, the presence or absence of crowding [21], and the patient esthetic expectations without forgetting that the esthetic perceptions can vary between dental professionals and laypersons. The orthodontist plays a key role in the treatment success, but it is undeniable that an excellent coordination between different practitioners in various specialties is crucial to avoid a possible treatment failure.

\section{References}

1. Yemitan TA, Adediran VE, Ogunbanjo BO (2017) Pattern of agenesis and morphologic variation of the maxillary lateral incisors in nigerian orthodontic patients. J West Afr Coll Surg 7(1): 71-91.

2. Gracco ALT, Zanatta S, Forin Valvecchi F, Bignotti D, Perri A, et al. (2017) Prevalence of dental agenesis in a sample of Italian orthodontic patients: an epidemiological study. Prog Orthod 18(1): 33.

3. Bozga A, Stanciu RP, Mănuc D (2014) A study of prevalence and distribution of tooth agenesis. J Med Life 7(4): 551-554.

4. Dallel I, Marwen W, Ben Abdallah S, Tobji S, Ben Amor A, et al. (2018) Agenesis of the upper lateral incisors: Study of an orthodontic population and clinical illustration. Int Orthod 16(2): 384-407.

5. Rølling S, Poulsen S (2009) Agenesis of permanent teeth in 8138 Danish schoolchildren: prevalence and intra-oral distribution according to gender. Int J Paediatr Dent 19(3): 172-175.

6. Higashihori N, Takada JI, Katayanagi M, Takahashi Y, Moriyama K (2018) Frequency of missing teeth and reduction of mesiodistal tooth width in Japanese patients with tooth agenesis. Prog Orthod 19(1): 30.

7. Citak M, Cakici EB, Benkli YA, Cakici F, Bektas B, et al. (2016) Dental anomalies in an orthodontic patient population with maxillary lateral incisor agenesis. Dental Press J Orthod 21(6): 98-102.

8. Bassiouny DS, Afify AR, Baeshen HA, Birkhed D, Zawawi KH (2016) Prevalence of maxillary lateral incisor agenesis and associated skeletal characteristics in an orthodontic patient population. Acta Odontol Scand 74(6): 456-459.

9. Arandi NZ, Mustafa S (2018) Maxillary lateral incisor agenesis; A retrospective cross-sectional study. Saudi Dent J 30(2): 155-160.

10. Celikoglu M, Kamak H, Yildirim H, Ceylan I (2012) Investigation of the maxillary lateral incisor agenesis and associated dental anomalies in an orthodontic patient population. Med Oral Patol Oral Cir Bucal 17(6): e1068-e1073.

11. Lamas C, Lavall A, Pinho T (2018) Position and Eruption of Permanent Maxillary Canines in Cases of Maxillary Lateral Incisor Agenesis in Mixed Dentition. J Clin Pediatr Dent 42(3): 240-246.

12. Priest G (2019) The treatment dilemma of missing maxillary lateral incisors-Part I: Canine substitution and resin-bonded fixed dental prostheses. J Esthet Restor Dent 31(4): 311-318.

13. Al-Jewair TS, Swiderski B (2016) Prosthetic replacement vs space closure for maxillary lateral incisor agenesis: A systematic review. Silveira GS, Almeida NV, Pereira DMT, Mattos CT, Mucha JN. Am J Orthod Dentofacial Orthop 150(2): 228-237.

14.Zachrisson BU, Rosa M, Toreskog S (2011) Congenitally missing maxillary lateral incisors: canine substitution. Point. Am J Orthod Dentofacial Orthop 139(4): 434.

15. Souza RA, Alves GN, Mattos JM, Coqueiro RDS, Pithon MM, et al. (2018) Perception of attractiveness of missing maxillary lateral incisors replaced by canines. Dental Press J Orthod 23(5): 65-74.

16. Mota A, Pinho T (2016) Esthetic perception of maxillary lateral incisor agenesis treatment by canine mesialization. Int Orthod 14(1): 95-107.

17. Schneider U, Moser L, Fornasetti M, Piattella M, Siciliani G (2016) Esthetic evaluation of implants vs canine substitution in patients with congenitally missing maxillary lateral incisors: Are there any new insights? Am J Orthod Dentofacial Orthop 150(3): 416-424.

18. Bizetto MS, Tessarollo FR, Jimenez EE, Guariza-Filho O, Camargo ES, et al. (2013) Implant rehabilitation of canines in case of bilaterally missing maxillary lateral incisors. Am J Orthod Dentofacial Orthop 144(1): 110-118.

19. Pini NI, Marchi LM, Pascotto RC (2015) Congenitally missing maxillary lateral incisors: update on the functional and esthetic parameters of patients treated with implants or space closure and teeth recontouring. Open Dent J 8: 289-294. 
20. Winitsky N, Olgart K, Jemt T, Smedberg JI (2018) A retro-prospective long-term follow-up of Brånemark single implants in the anterior maxilla in young adults. Part 1: Clinical and radiographic parameters Clin Implant Dent Relat Res 20(6): 937-944.
21. Silveira GS, de Almeida NV, Pereira DM, Mattos CT, Mucha JN (2016) Prosthetic replacement vs space closure for maxillary lateral incisor agenesis: A systematic review. Am J Orthod Dentofacial Orthop 150(2): 228-237.

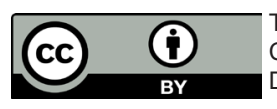

This work is licensed under Creative Commons Attribution 4.0 License DOI: 10.19080/ADOH.2020.13.555861

\section{Your next submission with Juniper Publishers} will reach you the below assets

- Quality Editorial service

- Swift Peer Review

- Reprints availability

- E-prints Service

- Manuscript Podcast for convenient understanding

- Global attainment for your research

- Manuscript accessibility in different formats ( Pdf, E-pub, Full Text, Audio)

- Unceasing customer service

Track the below URL for one-step submission https://juniperpublishers.com/online-submission.php 